\title{
Effect of Nursing Teaching Protocol on The Lifestyle Modification of Male Patients With Ischemic Heart Disease
} Yasmeen Mohamed Ali, Sahar Ali Abd-Elmohsen, Mohammed Hossam Eldin Hassan.

Nurse specialist at Directorate of Health Affairs, New Valley Governorate, Egypt. Lecturer of Medical Surgical Nursing, Adult nursing Department, Faculty of Nursing, Assiut University, Egypt. Professor of Internal Medicine, Faculty of Medicine, Assiut University, Egypt.

\begin{abstract}
Aim; evaluate the effect of nursing teaching protocol on the lifestyle modification of male patients with ischemic heart disease (IHD) through the following: 1- assess the lifestyle of male patients with IHD, 2- design and implement nursing teaching protocol (teaching booklet) on the lifestyle modification of male patients with IHD, 3evaluate the effect of applying a designed nursing teaching protocol on the lifestyle modification of male patients with IHD. Subjects \& methods: the study was conducted in the internal medicine department and outpatient internal medicine clinic at El Kharga general hospital In New Valley governorate. A convenience sample of 50 adult IHD patients aged between $(18-65)$ years old. This sample was divided into two equal groups; the study and the control groups (25 patients for each). Tool: - Patient pattern lifestyle assessment sheet (PPLSAS) (Pre and post [after application of the teaching protocol, after two moths]). Results: showed that there was a statistically significant difference between the study \&control group during the follow up period regarding health behavior ( $\mathrm{P}$. value 0.007), psychological aspect (P. value 0.031), and knowledge (P. value 0.001). Conclusion: the lifestyle of male patients with IHD who received the nursing teaching protocol was better than those who received the routine hospital care. Recommendations: establishment of patients educational centers in hospitals equipped by suitable related materials, media and audio-visual aids for teaching all ischemic heart disease patients how to modify their lifestyle based on their current condition.
\end{abstract}

\section{Key Words: Nursing Teaching Protocol, Lifestyle Modification \& Ischemic Heart Disease.}

\section{Introduction}

Cardiovascular disease (CVD) is a broadly defined classification of pathologic conditions that include: hypertension, coronary artery disease (CAD), myocardial infarction (MI or "heart attack"), angina pectoris, cerebrovascular accident (CVA or "stroke"), congestive heart failure (CHF), peripheral vascular disease (PVD), and sudden cardiac death. CVDs are the number one cause of death globally: more people die annually from CVDs than from any other cause. An estimated 17.3 million people died from CVDs in 2008 , representing $30 \%$ of all global deaths. Of these deaths, an estimated 7.3 million were due to coronary heart disease and 6.2 million were due to stroke (WHO 2011). In Egypt, according to the World Health Organization (WHO) data published in April 2011 coronary heart disease deaths reached $21.73 \%$ of total deaths (WHO 2012).

Ischemic heart disease (IHD) is the most common type of cardiovascular disease and accounts for the majority of these deaths. It also called coronary heart disease, results from a complex process known as atherosclerosis. In atherosclerosis, fatty deposits (plaques) of cholesterol and cellular waste products build up in the inner lining of the heart's arteries. This causes blockage of arteries (ischemia) and prevents oxygen-rich blood from reaching the heart (Morrow \& Gresh 2009).
The atherosclerosis process begins with cholesterol and lipoproteins that transport cholesterol. Cholesterol is a substance found in animal-based foods. It is critical for many functions, but under certain conditions cholesterol can be harmful. The lipoproteins that transport cholesterol are referred to by their size. The most commonly known are lowdensity lipoproteins (LDL) and high density lipoproteins (HDL). LDL is often referred to as "bad" cholesterol; HDL is often called "good" cholesterol (Ridker \& Libby. 2009).

A common symptom of ischemic heart disease (IHD) is angina. Angina is chest pain or discomfort that occurs if an area of the heart muscle doesn't get enough oxygen-rich blood. Angina may feel like pressure or squeezing in the chest, shoulders, arms, neck, jaw, or back. Angina pain may even feel like indigestion. The pain tends to get worse with activity and go away with rest. Emotional stress also can trigger the pain. Another common symptom of IHD is shortness of breath. The severity of these symptoms varies. They may get more severe as the buildup of plaque continues to narrow the coronary arteries (Boesner et al., 2010). 
IHD is related to lifestyle and physiological factors that, if modified, reduce morbidity and mortality. Individuals with proven vascular disease should be targeted for intensive lifestyle interventions. However, lifestyle intervention should be advised for everyone because of its overall health gain. Nutrition constitutes a key element in one's lifestyle and nutritional changes can impact many of the known risk factors included blood lipid abnormalities, hypertension, diabetes, smoking, physical inactivity and obesity (Al-Sarraj et al., 2010).

IHD might be preventable if an appropriate lifestyle was adapted. The utilization of prescription drugs to modify certain risk factors reduces the risk of IHD, as well as increases life expectancy and maintains health. Management of IHD risk factors with pharmaceuticals alone is rarely as effective as a combination therapy of lifestyle modification and pharmaceutical intervention. Most clinicians prefer to recommend lifestyle modifications prior to the initiation of drug therapy (Yusuf et al., 2008).

Nurses have an ideal opportunity to enhance healthpromoting activities that can reduce the risk of IHD as educators and role models for their patients, it is important that nurses consider the psychosocial and cultural parameters that may affect health behaviors. Nurses should be able to spend time to examine the patient's issues and provide solution. For example, smoking cessation, physical activity, nutrition and stress management and weight counseling are all areas where nurses may help to reduce the risk factors of IHD (Bishop \& Jackson. 2013).

\section{Aim of the study}

Evaluate the effect of nursing teaching protocol on the lifestyle modification of male patients with ischemic heart disease (IHD) through the following:

- Assess the lifestyle of male patients with IHD.

- Design and implement nursing teaching protocol (teaching booklet) on the lifestyle modification of male patients with IHD.

- Evaluate the effect of applying a designed nursing teaching protocol on the lifestyle modification of male patients with IHD.

\section{Research hypothesis}

To fulfill the aim of the study the following research hypothesis will formulate:

The lifestyle of male patients with IHD who will receive the nursing teaching protocol will be better than those who receive the routine hospital care.

Subjects and methods:

Research design: Quasi-experimental research design was utilized in this study.

\section{Setting}

The study was conducted in the internal medicine department and outpatient internal medicine clinic at El Kharga general hospital In New Valley governorate, during the period from September 2015 to March 2016.

\section{Subjects}

The study included a convenience sample of 50 adult ischemic heart disease male patients. Their ages ranged from 18 to 65 years. This sample was divided into two equal groups; the study and the control groups (25 patients for each). The control group who received the routine hospital care, and the study group with whom the nursing teaching protocol were applied by the researcher, a booklet for these guidelines was provided to them, and they were followed up after 2 months to assess the effect of applying the nursing teaching protocol.

Study tool

Patient pattern lifestyle assessment sheet (PPLSAS) (Pre and post [after application of the teaching protocol, after two months]): This tool was developed by Walker et al., (1987) to assess the lifestyle pattern of patients with ischemic heart disease, translated, modified, and adapted to the Egyptian culture by the researcher related to ischemic heart disease after reviewing the literature relevant to the study and with guidance of the supervisors in medical and nursing staff. It included 8 parts:

\section{Personal demographic data}

This part was specified for collection of the necessary data about study subjects. It included 14 items covering the following; patient's name, age, place of residence, marital status, level of education, occupation, socioeconomic status, duration of disease, family history of IHD and smoking history (5 items).

\section{Dietary pattern assessment}

It included 20 questions (questions from 1 to 20) covering the following items: regular three meals, use of snacks, use of canned food, eating fibers, use of alcohol, fat, coffee, excess sugar, excess salt, and eating in restaurants, amount of daily water consumption, if eating a healthy food, weight measure, eating problem, urinary problem and bowel problem.

\section{Physical activity}

It included 12 questions (questions from 21 to 32) covering the following items: activities of daily living, practicing exercise, duration, knowledge about the importance of exercise, if it is supervised by a physician, need for rest during work and sleep pattern.

Health aspects assessment

It included 14 questions (questions from 33 to 46) covering the following items: regular consultation 
with a doctor, measuring blood pressure, counting heart rate, doing laboratory investigation, observing body change, attending health programs, reading books, news, complying to prescribed medications, taking anthropometric measurements, vital signs and laboratory tests.

\section{Social support assessment}

It included 9 questions (questions from 47 to 55) covering the following items: avoiding isolation, keeping social relation, spending time with friends, expressing feelings, sharing concerns with others, sharing others concerns, if their illness had an effect on their life and if they are looking for new relations.

\section{Psychological aspect assessment \& stress} management

It included 9 questions (questions from 56 to 64) covering the following items: daily stressor, awareness of stressor sources, practicing daily relaxation, taking a nap during the day, falling asleep easily, having pleasant bedtime thoughts, receiving tranquilizers and the way of stress management.

\section{Self-concept assessment}

It included 11 questions (questions from 65 to 75) covering the following items: feeling different due to illness, feeling no change in being respected by others, having good spiritual life, having good hopes, feeling that illness is a punishment from God, having realistic future goals, feeling self-satisfied, feeling enthusiasm, feeling that illness is an obstacle and facing difficulties due to illness.

\section{$H$ : Patient information assessment regarding the disease}

It included 9 questions (questions from 76 to 84) covering the following items: own illness, complications, symptoms, investigations, normal values, treatment and prevention of disease.

Scoring system: Each item was categorized and scored into either:-

- Always $=2 \quad$ Sometimes $=1 \quad$ Never

$$
=0
$$

- The total score for all items was (84) points.

- Those who obtained less than (50\%) were considered having unhealthy lifestyle pattern.

- From (50\% to 70\%) were considered having satisfactory healthy lifestyle pattern.

- While those who obtained above (70\%) were considered having good healthy lifestyle pattern.

Nursing teaching protocol (teaching booklet)

The nursing teaching protocol (teaching booklet) was developed by the researcher based on patient's needs assessment, literature review, researcher experience and opinions of the medical and nursing staff. It was written in Arabic using simple language with illustration containing knowledge about:

- Brief explanation of the heart anatomy.
- Types, signs and symptoms of ischemic heart disease.

- Risk factors for the disease.

- Complications of the disease that might occur.

- Patient teaching on how to live with a healthy lifestyle patterns through covering the following:

- Smoking cessation.

- Dietary, physical, psychological health pattern.

- Drug management compliance.

Methods

- An official permission was obtained from the head of the internal medicine department to collect the necessary data, after explaining the aim and nature of the study.

- Pilot study was conducted on $10 \%$ (5) patients to examine clarity, applicability and feasibility of the study tool, the data obtained from the pilot study were analyzed, no change was done in the assessment sheet, so the 5 patients selected for the pilot study were included in the main study.

- The nursing teaching protocol was developed, after extensive literature review considering patient's needs and their levels of understanding.

- The purpose of the study was explained to the patients prior to answering the questions.

- The study was carried out in the morning, and afternoon shifts for all the available patients.

- The designed protocol was conducted through 2 theoretical sessions and the duration of each session was around 15 to 20 minutes.

- At the first interview the researcher introduced herself to initiate line of communication, explained the nature \& purpose of the study, collected the baseline (first) assessment using the tool (PLSPAS), and give brief explanation of the ischemic heart disease, types, signs, symptoms, and risk factors of it for the study group.

- The second interview was done for the study group which the guidelines on how to live with a healthy lifestyle patterns were explained for each patient and at the end of this session the teaching booklet was given to the patients to be used as a guide for them.

- The third interview was done two months after patient discharge from hospital to evaluate the effectiveness of the teaching protocol using (PLSPAS) and the purpose of this interview was to evaluate the effect of the teaching protocol on the level of knowledge and lifestyle pattern of those patients.

- The study was conducted in the internal medicine department and outpatient internal medicine clinic at El Kharga general hospital in New Valley governorate during the period from September 2015 to March 2016. 


\section{Content validity and reliability}

The tools were tested for content validity by 5 experts of (2 academic Tropical Medicine and gastroenterology staff and 3 nursing staff from faculty of Nursing) at Assuit University who reviewed the tools for clarity, relevance, comprehensiveness and understanding. Minor modifications were required and correction was carried out accordingly. Then the final form of the tool was designed and tested for reliability by using internal consistency for the tools measured using Cronbach test, the tools proved to be reliable (0.821).

Protection of human rights (ethical considerations)

- Research proposal was approved from ethical committee in the faculty of nursing.

- There was no risk for study subject during application of the research.

- The study was following common ethical principles in clinical research.

- Oral consent was obtained from patients or guidance who participated in the study, after explaining the nature and purpose of the study.

- Confidentiality and anonymity was assured.

- Study subject had the right to refuse to participate and or withdraw from the study without any rational any time.

- Study subject privacy was considered during collection of data.

\section{Statistical design}

The statistical analysis was interpreted to suit the research problem under investigation and was summarized in appropriate tables and charts. Data was entered in computer teaching protocols through SPSS Version 19. The following descriptive statistics tests, e.g. percentage, means and standard deviation were calculated. Tests for significance were applied, e.g. x2, paired t-test. A probability level of 0.05 was adopted as a level of significance for testing the research hypothesis. 


\section{Results}

Table (1): Personal demographic data of the studied groups (cont.).

\begin{tabular}{|c|c|c|c|c|c|}
\hline & \multicolumn{2}{|c|}{$\begin{array}{c}\text { Study } \\
(n=25)\end{array}$} & \multicolumn{2}{|c|}{$\begin{array}{l}\text { Control } \\
(n=25)\end{array}$} & \multirow[t]{2}{*}{ P-value } \\
\hline & No. & $\%$ & No. & $\%$ & \\
\hline \multicolumn{5}{|l|}{ Age: (years) } & \multirow{3}{*}{$0.015^{*}$} \\
\hline$<50$ years & 12 & 48.0 & 4 & 16.0 & \\
\hline$\geq 50$ years & 13 & 52.0 & 21 & 84.0 & \\
\hline \multicolumn{5}{|l|}{ Residence } & \multirow{3}{*}{0.417} \\
\hline Rural & 2 & 8.0 & 5 & 20.0 & \\
\hline Urban & 23 & 92.0 & 20 & 80.0 & \\
\hline \multicolumn{5}{|l|}{ Marital status } & \multirow{5}{*}{0.312} \\
\hline Single & 0 & 0.0 & 0 & 0.0 & \\
\hline Married & 24 & 96.0 & 25 & 100.0 & \\
\hline Divorced & 0 & 0.0 & 0 & 0.0 & \\
\hline Widow & 1 & 4.0 & 0 & 0.0 & \\
\hline \multicolumn{5}{|l|}{ Level of education } & \multirow{7}{*}{0.771} \\
\hline Illiterate & 0 & 0.0 & 1 & 4.0 & \\
\hline Read \& write & 0 & 0.0 & 0 & 0.0 & \\
\hline Primary & 2 & 8.0 & 2 & 8.0 & \\
\hline Preparatory & 1 & 4.0 & 2 & 8.0 & \\
\hline Secondary & 12 & 48.0 & 9 & 36.0 & \\
\hline University & 10 & 40.0 & 11 & 44.0 & \\
\hline \multicolumn{5}{|l|}{ Occupation } & \multirow{5}{*}{0.130} \\
\hline Employee & 10 & 40.0 & 16 & 64.0 & \\
\hline Free Business & 3 & 12.0 & 2 & 8.0 & \\
\hline Professional & 8 & 32.0 & 7 & 28.0 & \\
\hline Skilled & 4 & 16.0 & 0 & 0.0 & \\
\hline \multicolumn{5}{|l|}{ Family income } & \multirow{4}{*}{0.094} \\
\hline Less than enough & 1 & 4.0 & 6 & 24.0 & \\
\hline Enough & 22 & 88.0 & 16 & 64.0 & \\
\hline More than enough & 2 & 8.0 & 3 & 12.0 & \\
\hline \multicolumn{5}{|l|}{ Crowding index } & \multirow{3}{*}{--} \\
\hline Crowded & 2 & 8.0 & 2 & 8.0 & \\
\hline Not crowded & 23 & 92.0 & 23 & 92.0 & \\
\hline
\end{tabular}


Table (1): Personal demographic data of the studied groups.

\begin{tabular}{|c|c|c|c|c|c|}
\hline & \multicolumn{2}{|c|}{ Study $(n=25)$} & \multicolumn{2}{|c|}{ Control $(n=25)$} & \multirow{2}{*}{ P-value } \\
\hline & No. & $\%$ & No. & $\%$ & \\
\hline \multicolumn{5}{|c|}{ Duration of diagnosis } & \multirow{4}{*}{0.266} \\
\hline$<1$ year & 13 & 52.0 & 11 & 44.0 & \\
\hline $1-2$ years & 7 & 28.0 & 4 & 16.0 & \\
\hline$>2$ years & 5 & 20.0 & 10 & 40.0 & \\
\hline \multicolumn{5}{|c|}{ Family history of atherosclerosis } & \multirow{3}{*}{0.156} \\
\hline Yes & 14 & 56.0 & 9 & 36.0 & \\
\hline No & 11 & 44.0 & 16 & 64.0 & \\
\hline \multicolumn{5}{|l|}{ Smoking } & \multirow{4}{*}{0.741} \\
\hline Ex-smoker & 4 & 16.0 & 6 & 24.0 & \\
\hline Smoker & 10 & 40.0 & 10 & 40.0 & \\
\hline Non-smoker & 11 & 44.0 & 9 & 36.0 & \\
\hline \multicolumn{5}{|c|}{ Duration of smoking } & \multirow{4}{*}{0.264} \\
\hline $1-<5$ years & 4 & 40.0 & 2 & 20.0 & \\
\hline $5-10$ years & 0 & 0.0 & 2 & 20.0 & \\
\hline$>10$ years & 6 & 60.0 & 6 & 60.0 & \\
\hline \multicolumn{5}{|c|}{ Passive smoking } & \multirow{4}{*}{0.542} \\
\hline Always & 6 & 24.0 & 3 & 12.0 & \\
\hline Sometimes & 14 & 56.0 & 16 & 64.0 & \\
\hline Never & 5 & 20.0 & 6 & 24.0 & \\
\hline \multicolumn{5}{|c|}{ Tried to stop smoking } & \multirow{3}{*}{0.074} \\
\hline Yes & 3 & 30.0 & 7 & 70.0 & \\
\hline No & 7 & 70.0 & 3 & 30.0 & \\
\hline
\end{tabular}

Table (2): Comparison between the vital signs of the study group pre \& post application of the nursing teaching protocol.

\begin{tabular}{|l|c|c|c|}
\hline \multirow{2}{*}{} & Pre & Post & \multirow{2}{*}{ P-value } \\
\cline { 2 - 4 } & Mean \pm SD & Mean \pm SD & $0.001^{*}$ \\
\hline Pulse & $80.64 \pm 7.92$ & $70.76 \pm 4.94$ & $0.034^{*}$ \\
\hline Respiration & $25.00 \pm 2.55$ & $23.36 \pm 2.77$ & $0.001^{*}$ \\
\hline Systolic B.P & $145.00 \pm 13.54$ & $124.80 \pm 11.59$ & $0.001^{*}$ \\
\hline Diastolic B.P & $87.20 \pm 6.78$ & $78.40 \pm 6.88$ & ${ }^{*}$ \\
\hline
\end{tabular}

Table (3): Comparison between the vital signs of the control group pre and during the follow up period.

\begin{tabular}{|l|c|c|c|}
\hline \multirow{2}{*}{} & Pre & FU & \multirow{2}{*}{ P-value } \\
\cline { 2 - 4 } & Mean \pm SD & Mean \pm SD & $0.001^{*}$ \\
\hline Pulse & $86.08 \pm 9.74$ & $74.40 \pm 6.32$ & 0.823 \\
\hline Respiration & $24.84 \pm 2.69$ & $25.00 \pm 2.35$ & $0.008^{*}$ \\
\hline Systolic B.P & $147.60 \pm 26.50$ & $130.40 \pm 16.20$ & 0.061 \\
\hline Diastolic B.P & $86.20 \pm 14.53$ & $80.00 \pm 7.07$ & \\
\hline
\end{tabular}

Table (4): Comparison between the vital signs of the study and control group pre and post application of the nursing teaching protocol.

\begin{tabular}{|l|c|c|c|c|c|c|}
\hline \multirow{2}{*}{} & \multicolumn{3}{|c|}{ Pre } & \multicolumn{3}{c|}{ Post } \\
\cline { 2 - 5 } & Study & Control & \multirow{2}{*}{ P-value } & Study & Control & P-value \\
\cline { 2 - 5 } \cline { 5 - 8 } & Mean \pm SD & Mean \pm SD & & Mean \pm SD & Mean \pm SD & \\
\hline Pulse & $80.64 \pm 7.92$ & $86.08 \pm 9.74$ & $0.035^{*}$ & $70.76 \pm 4.94$ & $74.40 \pm 6.32$ & $0.028^{*}$ \\
\hline Respiration & $25.00 \pm 2.55$ & $24.84 \pm 2.69$ & 0.830 & $23.36 \pm 2.77$ & $25.00 \pm 2.35$ & $0.028^{*}$ \\
\hline Systolic B.P & $145.00 \pm 13.54$ & $147.60 \pm 26.50$ & 0.664 & $124.80 \pm 11.59$ & $130.40 \pm 16.20$ & 0.166 \\
\hline Diastolic B.P & $87.20 \pm 6.78$ & $86.20 \pm 14.53$ & 0.756 & $78.40 \pm 6.88$ & $80.00 \pm 7.07$ & 0.421 \\
\hline
\end{tabular}


Table (5): Assessment of patient knowledge of the study group pre \& post application of the nursing teaching protocol.

\begin{tabular}{|c|c|c|c|c|c|}
\hline & \multicolumn{2}{|c|}{ Pre } & \multicolumn{2}{|c|}{ Post } & \multirow{2}{*}{ P-value } \\
\hline & No. & $\%$ & No. & $\%$ & \\
\hline \multicolumn{5}{|l|}{ 1.Own illness } & \multirow{3}{*}{$0.050 *$} \\
\hline Yes & 20 & 80.0 & 25 & 100.0 & \\
\hline No & 5 & 20.0 & 0 & 0.0 & \\
\hline \multicolumn{5}{|l|}{ 2.Complications } & \multirow{3}{*}{$0.000 *$} \\
\hline Yes & 12 & 48.0 & 25 & 100.0 & \\
\hline No & 13 & 52.0 & 0 & 0.0 & \\
\hline \multicolumn{5}{|l|}{ 3.Investigation } & \multirow{3}{*}{$0.000 *$} \\
\hline Yes & 11 & 44.0 & 24 & 96.0 & \\
\hline $\mathrm{No}$ & 14 & 56.0 & 1 & 4.0 & \\
\hline \multicolumn{5}{|l|}{ 4.Normal values } & \multirow{3}{*}{$0.000 *$} \\
\hline Yes & 3 & 12.0 & 20 & 80.0 & \\
\hline No & 22 & 88.0 & 5 & 20.0 & \\
\hline \multicolumn{5}{|l|}{ 5.Treatment } & \multirow{3}{*}{$0.000 *$} \\
\hline Yes & 12 & 48.0 & 25 & 100.0 & \\
\hline No & 13 & 52.0 & 0 & 0.0 & \\
\hline \multicolumn{5}{|l|}{ Definition of this disease } & \multirow{4}{*}{$0.000^{*}$} \\
\hline Complete correct & 0 & 0.0 & 25 & 100.0 & \\
\hline Incomplete correct & 20 & 80.0 & 0 & 0.0 & \\
\hline Incorrect & 5 & 20.0 & 0 & 0.0 & \\
\hline \multicolumn{5}{|l|}{ Symptoms of the disease } & \multirow{4}{*}{$0.000 *$} \\
\hline Complete correct & 0 & 0.0 & 25 & 100.0 & \\
\hline Incomplete correct & 20 & 80.0 & 0 & 0.0 & \\
\hline Incorrect & 5 & 20.0 & 0 & 0.0 & \\
\hline \multicolumn{6}{|c|}{ Actions that can be taken to reduce the complications of the disease } \\
\hline Taking medication & 20 & 80.0 & 25 & 100.0 & $0.050 *$ \\
\hline Full rest & 9 & 36.0 & 8 & 32.0 & 0.765 \\
\hline The reduction of vigorous activities & 0 & 0.0 & 14 & 56.0 & $0.000 *$ \\
\hline Reduction of the salt intake & 1 & 4.0 & 1 & 4.0 & -- \\
\hline Minimizing fluids & 0 & 0.0 & 0 & 0.0 & -- \\
\hline Positive cope with life stressors & 9 & 36.0 & 25 & 100.0 & $0.000 *$ \\
\hline Do not know & 2 & 8.0 & 0 & 0.0 & 0.490 \\
\hline \multicolumn{6}{|l|}{ Methods of treatment of this disease } \\
\hline Taking medication & 20 & 80.0 & 25 & 100.0 & $0.050 *$ \\
\hline Full rest & 9 & 36.0 & 8 & 32.0 & 0.765 \\
\hline The reduction of vigorous activities & 0 & 0.0 & 15 & 60.0 & $0.000 *$ \\
\hline Reduction of the salt intake & 1 & 4.0 & 1 & 4.0 & -- \\
\hline Minimizing fluids & 0 & 0.0 & 0 & 0.0 & -- \\
\hline Positive cope with life stressors & 9 & 36.0 & 25 & 100.0 & $0.000 *$ \\
\hline Surgical intervention & 1 & 4.0 & 15 & 60.0 & $0.000 *$ \\
\hline Do not know & 2 & 8.0 & 0 & 0.0 & 0.490 \\
\hline
\end{tabular}


Table (6): Assessment of patient knowledge of the control group pre \& during the follow up period.

\begin{tabular}{|c|c|c|c|c|c|}
\hline & \multicolumn{2}{|c|}{ Pre } & \multicolumn{2}{|c|}{$\mathbf{F U}$} & \multirow{2}{*}{ P-value } \\
\hline & No. & $\%$ & No. & $\%$ & \\
\hline \multicolumn{5}{|l|}{ 1.0wn illness } & \multirow{3}{*}{0.349} \\
\hline Yes & 21 & 84.0 & 24 & 96.0 & \\
\hline No & 4 & 16.0 & 1 & 4.0 & \\
\hline \multicolumn{5}{|l|}{ 2.Complications } & \multirow{3}{*}{0.248} \\
\hline Yes & 13 & 52.0 & 17 & 68.0 & \\
\hline No & 12 & 48.0 & 8 & 32.0 & \\
\hline \multicolumn{5}{|l|}{ 3.Investigation } & \multirow{3}{*}{0.156} \\
\hline Yes & 11 & 44.0 & 16 & 64.0 & \\
\hline No & 14 & 56.0 & 9 & 36.0 & \\
\hline \multicolumn{5}{|l|}{ 4.Normal values } & \multirow{3}{*}{0.544} \\
\hline Yes & 7 & 28.0 & 9 & 36.0 & \\
\hline No & 18 & 72.0 & 16 & 64.0 & \\
\hline \multicolumn{5}{|l|}{ 5.Treatment: } & \multirow{3}{*}{0.529} \\
\hline Yes & 17 & 68.0 & 19 & 76.0 & \\
\hline No & 8 & 32.0 & 6 & 24.0 & \\
\hline \multicolumn{5}{|l|}{ Definition of this disease } & \multirow{4}{*}{0.466} \\
\hline Complete correct & 3 & 12.0 & 3 & 12.0 & \\
\hline Incomplete correct & 17 & 68.0 & 20 & 80.0 & \\
\hline Incorrect & 5 & 20.0 & 2 & 8.0 & \\
\hline \multicolumn{5}{|l|}{ Symptoms of the disease } & \multirow{4}{*}{0.466} \\
\hline Complete correct & 3 & 12.0 & 3 & 12.0 & \\
\hline Incomplete correct & 17 & 68.0 & 20 & 80.0 & \\
\hline Incorrect & 5 & 20.0 & 2 & 8.0 & \\
\hline \multicolumn{6}{|c|}{\begin{tabular}{|l|} 
Actions that can be taken to reduce the complications of the disease \\
\end{tabular}} \\
\hline Taking medication & 21 & 84.0 & 24 & 96.0 & 0.349 \\
\hline Full rest & 8 & 32.0 & 5 & 20.0 & 0.333 \\
\hline The reduction of vigorous activities & 1 & 4.0 & 2 & 8.0 & 0.552 \\
\hline Reduction of the salt intake & 1 & 4.0 & 1 & 4.0 & -- \\
\hline Minimizing fluids & 1 & 4.0 & 1 & 4.0 & -- \\
\hline Positive cope with life stressors & 9 & 36.0 & 17 & 68.0 & $0.024 *$ \\
\hline Do not know & 3 & 12.0 & 0 & 0.0 & 0.235 \\
\hline \multicolumn{6}{|l|}{ Methods of treatment of this disease } \\
\hline Taking medication & 21 & 84.0 & 24 & 96.0 & 0.349 \\
\hline Full rest & 8 & 32.0 & 5 & 20.0 & 0.333 \\
\hline The reduction of vigorous activities & 1 & 4.0 & 2 & 8.0 & 0.552 \\
\hline Reduction of the salt intake & 1 & 4.0 & 2 & 8.0 & 0.552 \\
\hline Minimizing fluids & 1 & 4.0 & 1 & 4.0 & -- \\
\hline Positive cope with life stressors & 9 & 36.0 & 18 & 72.0 & $0.011 *$ \\
\hline Surgical intervention & 4 & 16.0 & 9 & 36.0 & 0.107 \\
\hline Do not know & 3 & 12.0 & 0 & 0.0 & 0.235 \\
\hline
\end{tabular}


Table (7): Comparison between the patient knowledge of the study and control group post application of the nursing teaching protocol.

\begin{tabular}{|c|c|c|c|c|c|}
\hline & \multicolumn{2}{|c|}{ Study } & \multicolumn{2}{|c|}{ Control } & \multirow{2}{*}{ P-value } \\
\hline & No. & $\%$ & No. & $\%$ & \\
\hline \multicolumn{5}{|l|}{ 1.Own illness } & \multirow{3}{*}{0.312} \\
\hline Yes & 25 & 100.0 & 24 & 96.0 & \\
\hline No & 0 & 0.0 & 1 & 4.0 & \\
\hline \multicolumn{5}{|l|}{ 2.Complications } & \multirow{3}{*}{$0.004^{*}$} \\
\hline Yes & 25 & 100.0 & 17 & 68.0 & \\
\hline No & 0 & 0.0 & 8 & 32.0 & \\
\hline \multicolumn{5}{|l|}{ 3.Investigation } & \multirow{3}{*}{$0.005^{*}$} \\
\hline Yes & 24 & 96.0 & 16 & 64.0 & \\
\hline No & 1 & 4.0 & 9 & 36.0 & \\
\hline \multicolumn{5}{|l|}{ 4.Normal values: } & \multirow{3}{*}{$0.002^{*}$} \\
\hline Yes & 20 & 80.0 & 9 & 36.0 & \\
\hline No & 5 & 20.0 & 16 & 64.0 & \\
\hline \multicolumn{5}{|l|}{ 5.Treatment } & \multirow{3}{*}{$0.022 *$} \\
\hline Yes & 25 & 100.0 & 19 & 76.0 & \\
\hline No & 0 & 0.0 & 6 & 24.0 & \\
\hline \multicolumn{5}{|l|}{ Definition of this disease } & \multirow{4}{*}{$0.000 *$} \\
\hline Complete correct & 25 & 100.0 & 3 & 12.0 & \\
\hline Incomplete correct & 0 & 0.0 & 20 & 80.0 & \\
\hline Incorrect & 0 & 0.0 & 2 & 8.0 & \\
\hline \multicolumn{5}{|l|}{ Symptoms of the disease } & \multirow{4}{*}{$0.000^{*}$} \\
\hline Complete correct & 25 & 100.0 & 3 & 12.0 & \\
\hline Incomplete correct & 0 & 0.0 & 20 & 80.0 & \\
\hline Incorrect & 0 & 0.0 & 2 & 8.0 & \\
\hline \multicolumn{6}{|c|}{ Actions that can be taken to reduce the complications of the disease } \\
\hline Taking medication & 25 & 100.0 & 24 & 96.0 & 0.312 \\
\hline Full rest & 8 & 32.0 & 5 & 20.0 & 0.333 \\
\hline The reduction of vigorous activities & 14 & 56.0 & 2 & 8.0 & $0.000 *$ \\
\hline Reduction of the salt intake & 1 & 4.0 & 1 & 4.0 & -- \\
\hline Minimizing fluids & 0 & 0.0 & 1 & 4.0 & 0.312 \\
\hline Positive cope with life stressors & 25 & 100.0 & 17 & 68.0 & $0.004 *$ \\
\hline Do not know & 0 & 0.0 & 0 & 0.0 & -- \\
\hline \multicolumn{6}{|l|}{ Methods of treatment of this disease } \\
\hline Taking medication & 25 & 100.0 & 24 & 96.0 & 0.312 \\
\hline Full rest & 8 & 32.0 & 5 & 20.0 & 0.333 \\
\hline The reduction of vigorous activities & 15 & 60.0 & 2 & 8.0 & $0.000 *$ \\
\hline Reduction of the salt intake & 1 & 4.0 & 2 & 8.0 & 0.552 \\
\hline Minimizing fluids & 0 & 0.0 & 1 & 4.0 & 0.312 \\
\hline Positive cope with life stressors & 25 & 100.0 & 18 & 72.0 & $0.010^{*}$ \\
\hline Surgical intervention & 15 & 60.0 & 9 & 36.0 & 0.089 \\
\hline Do not know & 0 & 0.0 & 0 & 0.0 & -- \\
\hline
\end{tabular}




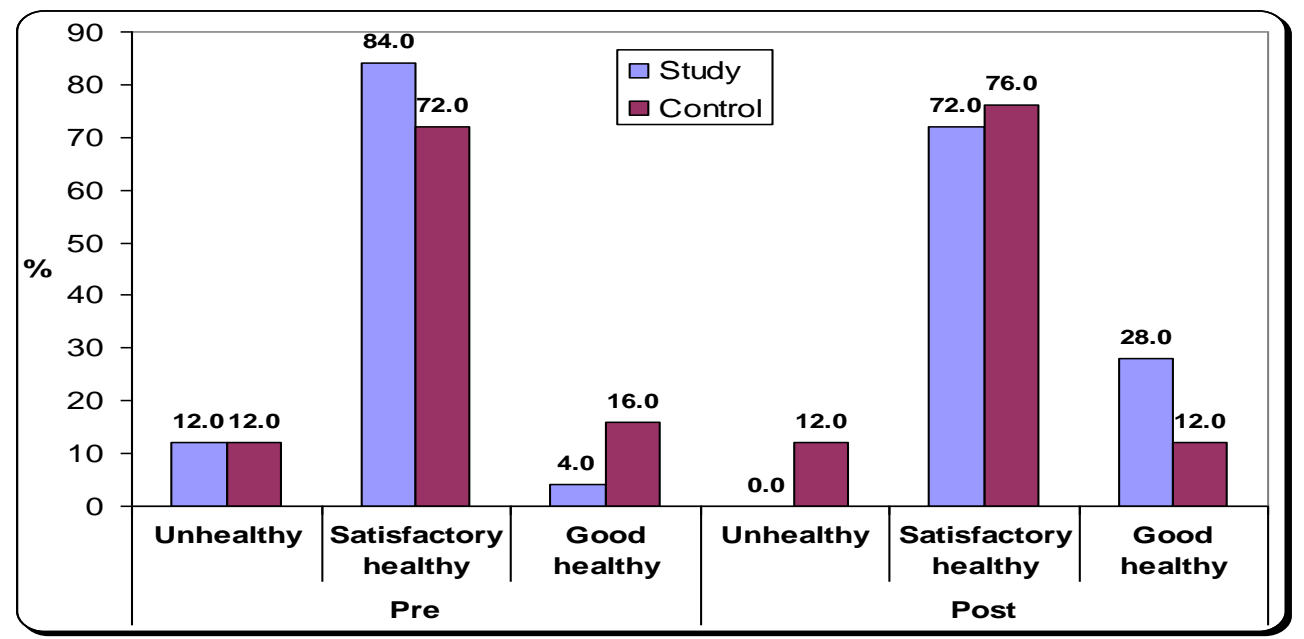

Figure (1): Comparison between study and control group pre and during the follow up period as regard lifestyle pattern.

Table (1): This table shows that the majority of the sample (study and control group), (68\%) their age was $\geq 50$ years, were living in urban, $(86 \%)$ married, $(42 \%)$ of them were having university education, employed (52\%), their income was enough $(76 \%)$ and they were not crowdedly indexed with a percentage of $(92 \%)$. Regarding duration of the disease $(48 \%)$ of them was less than 1 year, $(56 \%)$ of the study group were having a family history for atherosclerosis while this percent was (64\%) in the control group. An equal percent for smoking was found in both group (the study and control) (40\%). $(60 \%)$ of smokers in both the study and control groups have smoked for more than 10 years. $(60 \%)$ of both groups reported that they were sometimes exposed to passive smoking, while (18\%) of both groups reported that they were always exposed to passive smoking. Finally (70\%) of the smokers in the control group tried to stop smoking while in the study group only (30\%) tried to stop smoking.

Table (2): Shows that there was a highly statistically significant difference pre and post application of the study regarding vital signs measurement especially pulse and blood pressure (P value 0.001$)$.

Table (3): Shows that there was statistically significant difference pre and after follow up period of the control group regarding vital signs measurement especially pulse and blood pressure.

Table (4): This table shows that, there are statistically significant differences between the study and control group pre application of nursing teaching protocol regarding only pulse measurement, and there are statistically significant difference between the study and control group post application of nursing teaching protocol regarding pulse and respiration measurements.
Table (5): This table shows that, the patients in the study group reported that they have knowledge on their own illness with a percent of $(80 \%)$ pre study and $(100 \%)$ after application of nursing teaching protocol. Regarding their knowledge about complications of their illness the percent was (48\%) pre and this raised to (100\%) after the study. Their knowledge about laboratory investigations was (44\%), jumped to $(96 \%)$ after application of the protocol, the percent of their knowledge about normal values of laboratory investigations was (12\%) and raised dramatically to (80\%) after application of the protocol. Looking at their knowledge as regard their medication the percent was (48\%), raised to $(100 \%)$ after application of the protocol. Regarding their knowledge about the complete definition and symptoms of the disease, the percent raised dramatically from $(0 \%)$ to $(100 \%)$ after the study. When they were asked about the actions taken to reduce complications of the disease; $(80 \%)$ of them reported that taking medication is the best thing to do, this percent raised to $(100 \%)$ after the study, and (36\%) of them also reported that positive cope with life stressors is a measure taken to reduce complications, this percent raised dramatically to $(100 \%)$ after the study.

Table (6): This table shows that, patients in the control group reported that they have knowledge on their own illness with a percent of $(84 \%)$ and this percent raised to $(96 \%)$ during the follow up period. Regarding their knowledge about complications of their illness the result was (52\%) pre and this percent raised to $(68 \%)$ during the follow up period. Their knowledge about laboratory investigations was (44\%) and this percent raised to (64\%) during the follow up period, the percent of their knowledge about normal values of laboratory investigations was (28\%) and 
this percent became (36\%) during the follow up period. Looking at regular taking of their medication the percent was $(68 \%)$, this percent has reached (76\%) during the follow up period. Regarding their knowledge about the complete definition and symptoms of the disease the percent was (12\%) pre and during the follow up period. When they were asked about the actions taken to reduce complications of the disease; $(84 \%)$ of them reported that taking medications is the best thing to do, this percent raised to $(96 \%)$ during the follow up period, and $(36 \%)$ of them also reported that positive cope with life stressors is a measure taken to reduce complications and this percent raised to $(68 \%)$ during the follow up period.

Table (7): This table shows that, there are statistically significant differences between the study and control group post application of nursing teaching protocol regarding their knowledge about definition, symptoms, complications, investigations, and treatment of their disease.

Figure (1): This figure shows that the study group pre application of the nursing teaching protocol has good healthy lifestyle pattern with percent $(4 \%)$, and after application of the nursing teaching protocol they has good healthy lifestyle pattern with percent $(28 \%)$.

\section{Discussion}

The present study included 50 adult ischemic heart disease male patients, as the incidence of IHD is much more common in male than female, when comparing with international figures, there were also more men than women susceptible to coronary heart diseases (CHDs) (Go et al., 2013). Moreover, according to the statistics shown by the Department of Health (Centre for Health Protection, 2014), the crude death rates due to CHD were 75.9 for male and 45.7 for female per 100,000 population in 2012 . This constitutes a male to female ratio of around 1.7 to 1 . Regarding socio-demographic characteristics, the present study revealed that the majority of the sample (study and control) their age was more than 50 years old, this result was in agreement with the study done in 4 hospitals on 254 patients in Jordan to assess patients' adherence to healthy behavior in coronary heart disease by Sultan \& Muhammad (2013) who found that the mean age was 52 years.

In relation to residential area, the present study found that the majority of the studied sample (study and control) were from urban area while few of them from rural area. This result comes in agreement with the study done in North England to assess socioeconomic status and cardiovascular disease by Clark et al., (2009) who mentioned that amongst the majority of participants the place of life was urban and a few of participants was in rural locations.

Regarding marital status; the finding of the present study showed that nearly the entire studied sample (study group) except one was married. This result comes in agreement with the study by Mackenbach et al., (2008) which was conducted to assess socioeconomic inequalities in health in 22 European Countries reported that eighty percent of those interviewed were married and one fifth were widowed.

Regarding educational level among the studied sample (study and control); the results revealed that more than third of them were secondary educated, and the same percent were university educated. This result disagreed with the study done in Finland to assess difference between coronary artery disease (CAD) patients educational groups which conducted by Pekkanen et al., (2008) who reported that $70 \%$ of the studied sample were illiterate, $25 \%$ possessed no academic qualifications and just $5 \%$ were on the college graduate level.

As regard occupation; the present study showed that more than three quarters of the studied sample (study and control) were employee, less than one fifth were free business and a few of them were skilled workers. These results disagreed with the study done in Iran to assess the prevalence of coronary artery disease risk factors conducted by Hatmi et al., (2007) who found that the most common professions were housekeeper and retired, while just four percent of participants were unemployed, six percent of those interviewed had official/semi-official positions and twenty percent of the respondents were self-employed such as carpet weaving, selling, and tent making.

In relation to family history; the present study showed that more than two fifths of studied sample (study and control) were having a family history of IHD and most of them were first degree kinship, this result was in agreement with a study conducted by Humphries et al., (2010) about coronary heart disease risk prediction in the Era of Genome-wide association studies who reported the existence of close (first-degree) relatives who had an acute coronary syndrome, such as a myocardial infarction. Regarding the smoking habits among patients (study and control group) in the present study; more than three quarters of them were exposed to passive smoking, also more than one fifth of them smoked for a duration of more than 10 years. Smoking habits is considered a risk factor for ischemic heart disease this result coincided with a study by Bonita (2009) in New Zealand on passive smoking as well as active smoking increases the risk of acute stroke, and high blood pressure. 
In relation to patient's vital signs measurements; the present study showed that there was a highly statistically significant difference pre and post application of the study regarding vital signs measurement especially pulse and blood pressure. This study measurements were in agreement with Mancia et al., (2009) in a study on European society indicated that; particular attention should be given to control of elevated BP. There is sufficient evidence to recommend that systolic $\mathrm{BP}$ (SBP) be lowered to 140 $\mathrm{mmHg}$ and diastolic BP (DBP) to $90 \mathrm{mmHg}$ in CAD patients with hypertension.

Regarding knowledge about the disease; pre application of the protocol more than two thirds of patients have incomplete correct definition and symptoms of the disease compared to all of them have complete answer after application of the teaching protocol. This is congruent with Hassan, (2007) who conducted a study on 20 patients at Coronary Care Unit in Iraq to evaluate the effectiveness of cardiac teaching program on patients with acute myocardial infarction and reported that patients' knowledge about the definition of MI and its causes improved post cardiac teaching program.

These results were supported by Abdelhameed et al., (2013) who studied the impact of a designed nursing intervention protocol on myocardial infarction patient's outcomes among $40 \mathrm{MI}$ patients from the cardiac care unit at Cairo University Hospital, Egypt. They found that, the post total mean knowledge scores of the studied subjects was increased significantly as a result of program implementation.

Regarding patients' knowledge about treatment of the disease; nearly half of them pre application of the teaching protocol reported that they knew the treatment of their disease compared to all of them have known it after application of the protocol. Similar results were reported by Alkatheri, \& Albekairy, (2013) who conducted a study on 90 patients with chronic diseases as cardiovascular, hypertension and diabetes in inpatient and outpatient settings in Saudi Arabia to evaluate the effect of patients' educational level and previous counseling on medication knowledge. They reported that, the majority of patients who received previous counseling showed good to excellent recognition of their medications.

Regarding measures taken to reduce complications of the diseases; the studied sample reported after application of the teaching protocol that they were taking the medication, reducing vigorous activities, coping with life stressors and getting for full rest to reduce complications. These results coincided with study by Elaskary, (2011) who assessed the impact of health promotion program on compliance with therapeutic regimen among 300 hypertensive patients in Gaza Strip, and found that, the most important benefits identified by the participants were protection from complication, followed by avoidance of additional finance to treat complications, keeping blood pressure under control, maintaining a sense of wellbeing, maintaining good health and improving quality of health.

Regarding total lifestyle practices; the present study showed that there was a statistically significant difference between the study and control group after follow up period as regard health behavior domain with a P. value of (0.007), psychological aspect with a P. value of (0.031), and knowledge with a $P$. value of $(0.001)$, while there was no statistically significant difference between nutrition, social support, and selfesteem domain after follow up period. The findings revealed that the study group pre application of the nursing teaching protocol has good healthy lifestyle pattern with percent 4 , and after application of the nursing teaching protocol they has good healthy lifestyle pattern with percent 28 .

Similar to the results of this study, a study by Jiang et al., (2007) indicated that, a nurse-led cardiac rehabilitation program can significantly improve the health behaviors and cardiac physiological risk factors in coronary heart disease patients. Also, Coulson et al., (2009) indicated that there was a significant main effect of the intervention program in all dependent health profile variables, in addition a significant interaction was found related to physical activity, nutrition, health responsibility and stress management, $\mathrm{P}<0001$.

\section{Conclusion}

Based on the results of the present study, it can be concluded that; the lifestyle of male patients with IHD who received the nursing teaching protocol (study group) was better than those who received the routine hospital care (control group). There was a statistically significant difference between the study and control group subjects regarding health behavior domain, psychological aspect, and knowledge post application of the nursing teaching protocol.

\section{Recommendations}

Based on the findings of the present study, the following recommendations are suggested:

- Establishment of patients' educational centers in hospitals equipped by suitable related materials, Medias and audio-visual aids for teaching all ischemic heart disease patients how to modify their lifestyle based on their current condition.

- Patients with ischemic heart disease must be followed up for high density lipoprotein (HDL) cholesterol, low density lipoprotein (LDL) 
cholesterol, and triglyceride level to follow progress of their condition.

\section{References}

1. Abdelhameed A., Mohammad W., Seloma Y., \& Zaghla H., (2013): Impact of a designed nursing intervention protocol on myocardial infarction patient's outcome at a selected University Hospital in Egypt. Journal of Biology, Agriculture and health care, Vol. 3, No.17, 2013.

2. Alkatheri A., Albekairy AM (2013): Does the patients' educational level and previous counseling affect their medication knowledge? Journal of Thoracic Medicine, 8(2): 105-108. Doi: 10.4103/1817-1737.109823.

3. Al-Sarraj T., Saadi H., Volek J., \& Fernandez M., (2010): Metabolic syndrome prevalence, Dietary Intake, and cardiovascular risk profile among overweight and obese adults 18 - 50 years old from the United Arab Emirates. p.p 8:39-46.

4. Bishop C., \& Jackson J., (2013): Motivational interviewing: how advanced practice nurses can impact the rise of chronic diseases. J Nurse Pract; 9(2):105-115.

5. Boesners S., Becker A., Keller H., Sonnichsen A., Haasenritter J, Karatolios K., Schaefer J., Baum E., \& Donner-Banzhoff N., (2010): Accuracy of symptoms and signs for coronary heart disease assessed in primary care. Brjgen Pract; p.p 60:246_257.

6. Bonita R., (2009): Passive smoking as well as active smoking increase the risk of acute stroke. Tobacco control, pp. 8:156-160.

7. Centre for Health Protection, Department of Health. (2014): Heart Diseases. Available at http://www.chp.gov.hk/en/content/9/25/57.html.

8. Clark A., Meules M., Luo W., Duncan AS, \& Wielgosz A (2009): Socioeconomic status and cardiovascular disease: Risks and implication for care. Nat Rev Cardio; 6:712-722.

9. Coulson F., Pinazar V., \& Margolis S., (2009): Awareness of risks of overweight among rural Australiants. Rural and Remote Health 6:514.

10. Elaskary E., (2011): Impact of health promotion program on compliance with therapeutic regimen among hypertensive patients in Gaza Strip. A dissertation submitted in partial fulfillment of the requirements for the degree of doctor of Nursing in Cairo University.

11. Go A., Mozaffarian D., Roger V., Benjamin E., Berry J., \& Blaha M., the American Heart Association Statistics Committee \& Stroke Statistics Subcommittee (2013): Heart disease and stroke statistics, 2014 Update. A report from the American Heart Association. Circulation, $129 . \quad$ Available athttp://circ.ahajournals.org/content/129/3/e28.fu 11.pdf+html.

12. Hassan H., (2007): To evaluate the effectiveness of cardiac teaching program on patients with acute myocardial infarction during the first stage of rehabilitation. Journal: Al-TAQANI, volume: 20: 54-63.

13. Hatmi Z., Tahvildari S., Gafarzadeh, Motlag A., Sabouri, \& Kashani A (2007): Prevalence of coronary artery disease risk factors in Iran: A population based survey. BMC Cardiovascular Dis; $7: 32$.

14. Humphries S., Drenos F., Ken-Dror G., \& Talmud P., (2010): Coronary heart disease risk prediction in the Era of Genome- Wide Association Studies: Current status and what the future holds. Circulation; 121:2235-2248.

15. Jenkins D., \& Gerred S., (2012): ECG library: Acute anterior myocardial infarction. Retrieved February from http://www.ecglibrary.com/ami.html.

16. Jiang X., Sit J., \& Wong T., (2007): A nurse Led cardiac rehabilitation program improves health behaviours and cardiac physiological risk parameters: Evidence From Chenhdu, Chengdu, china. J Clin Nurse; 16(10).

17. Mackenbach J., Stribu I., \& Roskam, AJR (2008): Socioeconomic inequalities in Health in 22 European Countries N Engl Med; 358:24682481.

18. Mancia N., Helmy T., \& Patel A., (2009): Evidence-based management of coronary heart disease in the elderly current perspectives, Med Gen Med 5:75.

19. Morrow D., \& Gersh B., (2009): Chronic Coronary Artery Disease, In: Bonow R.O, Boden W.E, Mann D.L, Zipes D.P, and Libby P: Braunwalds Heart Disease: A Textbook of Cardiovascular Medicine. $8^{\text {th }}$ ed. Philadelphia, PA: Elsevier Saunders, chap 54.

20. Pekkanen J., Uutela A., Valkonen T., Vartiainen E., Tuomilehto J., \& Puska P., (2008): Coronary risk factor levels: Differences between educational groups in Eastern Finland. J epidemiologic community health; 49(2):1444-9.

21. Ridker P., \& Libby P., (2009): Risk factors for atherothrombotic disease. A Textbook of Cardiovascular Medicine. $8^{\text {th }}$ ed. Philadelphia, PA: Elsevier Saunders, chap 39.

22. Sultan M., Mosleh, \& Muhammad Darawad (2013): Patients' Adherence to Healthy Behavior in Coronary Heart Disease, Journal of Cardiovascular Nursing .Copyright (C) 2014 
Wolters Kluwer Health Lippincott, Williams \& Wilkins.

23. Walker S., Sechrist K., \& Pender N., (1987): The Health- Promoting Lifestyle Profile: Development and psychometric characteristics. Nursing Research, 36 (2), 76-81.

24. World Health Organization (2012): Data and statistics: Mortality and Health Status. (Accessed January 12, 2012) Available from: http://www.who.int/research/en/.

25. World Health Organization (2011): Global status report on non-communicable diseases, updated March 2013.

26. Yusuf S., Hawken S., Ounpuu S., Dans T., \& McQueen M., (2008): Effect of potentially modifiable risk factors associated with myocardial infarction in 52 countries (The INTER HEART study): case-control study. Lancet, p.p 364; 937-52. 